\title{
Los mecanismos de cohesión textual en algunos cuentos de Julio Cortázar para el aprendizaje de $\mathrm{E} / \mathrm{LE}$
}

ISABEL PAULO SELVI

IES Els Évols

46021320@edu.gva.es

\begin{abstract}
Resumen: Los relatos de Cortázar constituyen una herramienta didáctica, dentro del paradigma comunicativo, que potencia una serie de recursos y de estrategias discursivas, con el objetivo de que el aprendiente de E/LE adquiera esta pragmática literaria en un dominio lingüístico de $\mathrm{C}$. El objetivo de la propuesta es analizar, orientar y valorar una selección de cuentos para mejorar el aprendizaje, por ello, las actividades propuestas van desarrollándose mediante relaciones léxico-semánticas. En buena medida, las estrategias pragmáticas (de seducción, de persuasión y de argumentación) se unen con algunos mecanismos discursivos, los cuales facilitan la cohesión textual. Para la aplicación didáctica es necesario: primero, cambiar el enfoque; segundo, pautar la lectura; tercero, mostrar el texto íntegro para trabajar algunas estrategias. La aplicación continuada de estas estrategias discursivas favorecerá el aprendizaje en el aula de E/LE.

Palabras clave: cohesión textual, Cortázar, estrategias, aprendizaje E/LE.

The mechanisms of textual cohesion in some stories by Julio Cortázar for the learning of $\mathbf{E} / \mathbf{L E}$
\end{abstract}

Abstract: The stories of Cortázar constitute a didactic tool, within the communicative paradigm, that promotes a series of resources and discursive strategies, with the objective that the E/LE learner acquires this literary pragmatics in a linguistic domain of C1.The objective of my paper is to analyze, guide and evaluate a selection of stories to improve learning, therefore, the proposed activities work are developed through axes for lexical-semantic relations. To a large extent, pragmatic strategies (of seduction, persuasion and argumentation) are combined with some discursive mechanisms, which facilitate textual cohesion. For the didactic application it is necessary: first, to change the focus; second, to guide the reading; third, show the full text to work on some strategies. The continued application of these discursive strategies will favor learning in the E/LE classroom.

Key words: textual cohesion, Cortázar, strategies, learning E/LE.

\section{Los principios constructivos de los relatos}

Los motivos temáticos en la obra de Cortázar surgen de la cotidianidad, por ello la organización del relato busca la ruptura con la linealidad lógico-temporal, establece el contraste y juega con la paradoja de la existencia bitemporal del sujeto. El relato es un tipo de texto narrativo «que encuentra su dinamismo organizativo en la isotopía de la transgresión» (Campra 2008: 193); sin embargo, a diferencia del relato clásico de lo fantástico, Cortázar realiza una transgresión semántica basada, en primer lugar, en la novedad temática de la imagen fantástica contemporánea; en segundo lugar, en el 
realismo y la verosimilitud del mundo representado junto con el carácter contradictorio; y en tercer lugar, en un empleo sistemático de «la reticencia narrativa» (Zeppegno 2013: 276).

En los cuentos no son habituales ni largas escenas ni cambios con pausas sino un dinamismo creado a través de las descripciones y los finales abiertos (como ejemplo el cuento Continuidad de los parques). La brevedad, la concisión y la precisión lingüística son esenciales en la configuración del cuento en Cortázar, puesto que las estrategias discursivas se desarrollan a través de las elipsis, del punto de vista variable, de los juegos temporales, además de la configuración de espacios como «una de las posibilidades y de las presencias que puede darnos la realidad cuando por algún motivo directo o indirecto alcanzamos a abrirnos a esas imprevisiones» (Cortázar 1980: 12).

Yurkievich (2004: 30) propone diez razones para leer a Cortázar: literaria, estética, fabulosa, existencial, erótica, lúdica, humorística, cultural, cognoscitiva y humana. Aquí se analizará el cuento como herramienta didáctica donde el docente pueda activar la reflexión y promover el desarrollo de la capacidad comunicativa en la clase de E/LE. Los textos que se presentan son materiales auténticos donde el alumno tiene que enfrentarse a muestras de lengua, además, han sido pensados con el propósito de disfrutar de la lectura, poseen un valor cultural beneficioso para la transmisión de códigos sociales, tienen una gran riqueza lingüística, y sobre todo, crean un compromiso personal del estudiante que se va involucrando en la historia al mismo tiempo que amplía sus conocimientos y sus competencias en la lengua meta. Son textos accesibles (con una información de entrada comprensible), significativos, motivadores e integradores de varias destrezas.

Las propuestas de trabajo dependerán de los criterios que se quieran destacar: la literatura como lenguaje, la literatura como contenido, la literatura como enriquecimiento personal o como objeto en contextos de L2 (Biedma Torrecillas 2007: 250). Sobre todo interesa desarrollar las estrategias lectoras para que el alumno pueda aprehender el sentido global del texto sin perderse en complejas operaciones de descodificación.

\section{La competencia discursiva}

La competencia comunicativa comprende diferentes áreas que se interrelacionan entre sí: la competencia gramatical, la discursiva, la sociolingüística y la estratégica (Canale y Swan 1983: 66). La competencia discursiva tiene que ver con las formas y significados de la gramática que permiten configurar un texto, con cohesión y coherencia. Bachman (1990: 111) propone una competencia textual que incluye el conocimiento de las convenciones para unir las frases y formar un texto estructurado conforme a la organización retórica. Alonso Belmonte (2004: 554 y ss.) analiza con detalle esta competencia y su evolución.

El Marco Común Europeo de Referencia de las Lenguas (MCERL) considera la competencia discursiva como una de las tres competencias pragmáticas y la define como «la capacidad que posee el usuario o alumno de ordenar oraciones en secuencias para producir fragmentos coherentes de lengua» (MCERL: §5.2.3.1). Del propio Marco se desprende que la enseñanza-aprendizaje de la competencia discursiva necesita de las habilidades y de las destrezas (saber hacer), de la capacidad de aprender (saber 
aprender) y de la competencia existencial (saber ser). Además, la competencia discursiva necesita de la competencia lingüística y de la sociolingüística.

El Plan Curricular del Instituto Cervantes (PCIC) comprende las funciones (cap.5), las tácticas y estrategias pragmáticas (cap. 6) y los géneros discursivos y productos sociales (cap. 7). En el capítulo dedicado a las tácticas y estrategias comunicativas analiza «los recursos de que dispone la lengua para emitir e interpretar enunciados con una determinada intención comunicativa, así como la interiorización de los procesos que permiten activar tácticas y estrategias para lograr el éxito de la comunicación» (PCIC 2006: 218). En definitiva, el planteamiento de ambos implica un enfoque del aprendizaje que tenga presente la necesidad de dotar a los aprendientes de «los recursos que se requieren para desenvolverse adecuadamente y con autonomía en las distintas situaciones de comunicación» (PCIC 2006: 40). El conocimiento de las estrategias discursivas y de los mecanismos de cohesión textual, son básicos para ayudar a la adquisición de la competencia pragmática del estudiante.

El análisis se basará en el estudio de las relaciones de discurso (Duque 2016), adaptándolo en este caso al relato de Cortázar, así como de la gramática pedagógica para tratar aspectos lingüísticos (Ruíz Campillo 2011).

\section{Aplicación práctica}

\subsection{El relato Casa Tomada}

El primer cuento Casa Tomada (a partir de ahora CT) es un ejemplo para la aplicación de estrategias discursivas. Se les da a los discentes de E/LE estos fragmentos del relato para que expresen hipótesis y predicciones sobre la historia:

(1) Pero es de la casa que me interesa hablar, de la casa y de Irene, porque yo no tengo importancia. Me pregunto qué hubiera hecho Irene sin el tejido.

(2) Fui por el pasillo hasta enfrentar la entornada puerta de roble, y daba la vuelta al codo que llevaba a la cocina cuando escuché algo en el comedor o la biblioteca. El sonido venía impreciso y sordo, como un volcarse de silla sobre la alfombra o un ahogado susurro de conversación. También lo oí, al mismo tiempo o un segundo después, en el fondo del pasillo que traía desde aquellas piezas hasta la puerta. Me tiré contra la puerta antes de que fuera demasiado tarde, la cerré de golpe [...].

(3) Los primeros días nos pareció penoso porque ambos habíamos dejado en la parte tomada muchas cosas que queríamos [...]. Y era una cosa más de todo lo que habíamos perdido al otro lado de la casa.

(4) No nos miramos siquiera. Apreté el brazo de Irene y la hice correr conmigo hasta la puerta cancel, sin volvernos hacia atrás. Los ruidos se oían más fuertes pero siempre sordos, a espaldas nuestras. Cerré de un golpe la puerta cancel y nos quedamos en el zaguán. Ahora no se oía nada.

(5) Rodeé con mi brazo la cintura de Irene (yo creo que ella estaba llorando) y salimos así a la calle. Antes de alejarnos tuve lástima, cerré bien la puerta de entrada y tiré la llave a la alcantarilla. No fuese que a algún pobre diablo se le ocurriera robar y se metiera en la casa, a esa hora y con la casa tomada. Cortázar, 1976:11.

La historia avanza en una transgresión temporal (el relato juega con la analepsis y la prolepsis), además de optar por una relajación consciente que retrasa la intriga hasta el final, en una claudicación de los personajes hacia su destino. El eje temporal está muy definido en el relato: se utiliza el pretérito imperfecto para los hechos cotidianos de la 
casa y el pretérito indefinido para el momento en que la casa empieza a ser tomada (esto se puede trabajar con los discentes desde el texto y con un enfoque desde la gramática pedagógica para que puedan ver la diferencia temporal):

NOSOTROS/ CASA

IRENE

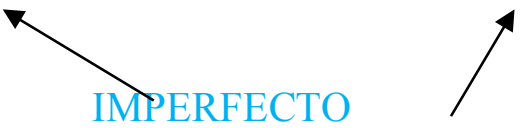

DISTRIBUCIÓN DE LA CASA
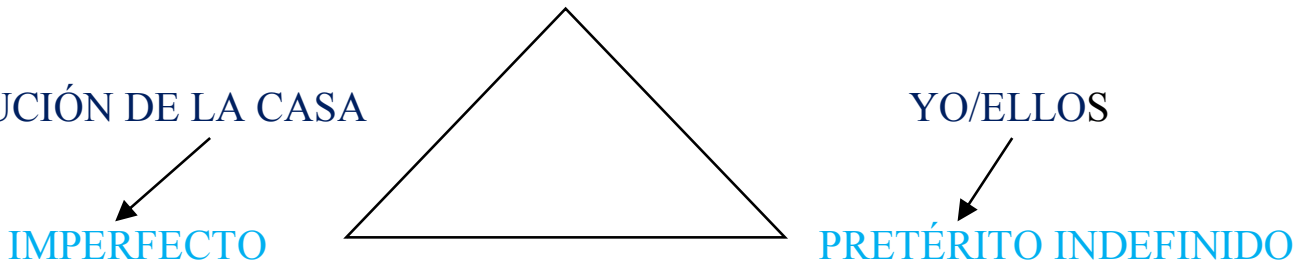

Figura 1. Representación del eje verbal del relato. Fuente propia.

El relato finaliza con el Pretérito Imperfecto de Subjuntivo para marcar las posibles acciones futuras respecto al pasado que dejan atrás los personajes en CT. Este juego con el eje temporal, como mecanismo de cohesión gramatical, es importante trabajarlo con los alumnos de E/LE en el aula:

(6) Como me quedaba el reloj pulsera, vi que eran las once de la noche. Rodeé con mi brazo la cintura de Irene (yo creo que ella estaba llorando) y salimos así a la calle. Antes de alejarnos tuve lástima, cerré bien la puerta de entrada y tiré la llave a la alcantarilla. No fuese que a algún pobre diablo se le ocurriera robar y se metiera en la casa, a esa hora y con la casa tomada.

Cortázar (1976:12)

Las relaciones discursivas son imprescindibles para que el alumno de E/LE tome conciencia de las mismas de cara a su posterior producción. Como ejemplo, se pueden organizar estas familias de relaciones en el relato:

(7) De semejanza: «Irene rechazó dos pretendientes sin mayor motivo, a mí se me murió María Esther antes que llegáramos a comprometernos». Relación de contraste con dos informaciones importantes para el relato, donde las señales que facilitan la identificación son los antropónimos, los pronombres personales y la valoración negativa de la Casa.

(8) De ampliación: «Cuando la puerta estaba abierta advertía uno que la casa era muy grande; si no, daba la impresión de un departamento de los que se edifican ahora, apenas para moverse; Irene y yo vivíamos siempre en esta parte de la casa, casi nunca íbamos más allá de la puerta de roble [...]». Los detalles describen el marco y es justamente el tiempo verbal del imperfecto el que permite la descripción de la situación, característica principal de la relación de circunstancia.

(9) De causalidad: «Los primeros días nos pareció penoso porque ambos habíamos dejado en la parte tomada muchas cosas que queríamos [...]. Y era una cosa más de todo lo que habíamos perdido al otro lado de la casa». En esta relación de causa (lo extraño) se produce la consecuencia (los personajes van retrocediendo hasta irse de la CT). La señal identificativa es el anafórico causal y la relación temporal que se establece.

Cortázar (1976: 10) 
No todas las relaciones del discurso se realizan con elementos léxicos delimitados, como los marcadores, sino también se emplean estructuras paralelas con una implicación lógica de los enunciados. Los mecanismos de referencia se basan en la deixis tanto personal (con el uso de los pronombres personales) como espacial (con los adverbios de lugar, por ejemplo: «No está aquí»); así como en el empleo de los mecanismos anafóricos (sobre todo con los pronombres relativos). La cohesión léxica se mantiene en elementos recurrentes que manifiestan una reticencia narrativa en el desarrollo del relato y con una sinonimia referencial que gira alrededor de la isotopía de la Casa. Los mecanismos lógico-sintácticos vienen determinados con marcadores conversacionales de valor consecutivo, como por ejemplo en el siguiente caso:

(10) Dejó caer el tejido y me miró con sus graves ojos cansados.

- ¿Estás seguro?

- Asentí.

-Entonces -dijo recogiendo las agujas- tendremos que vivir en este lado.

Cortázar (1976:10)

Cortázar logra en CT construir una red de relaciones cohesivas que forma parte del entramado lógico del relato. A partir de aquí es conveniente trabajar con pequeños fragmentos de CT para facilitar el proceso de aprendizaje autónomo en el discente de E/LE. A continuación, se extractan aquellos fragmentos del relato que focalizan la cotidianidad a través de los quehaceres domésticos:

(11) Hacíamos la limpieza por la mañana, levantándonos a la siete, y a eso de las once yo le dejaba a Irene las últimas habitaciones por repasar y me iba a la cocina. Almorzábamos a mediodía, siempre puntuales; ya no quedaba nada por hacer fuera de unos pocos platos sucios. Nos resultaba grato almorzar pensando en la casa profunda y silenciosa y cómo nos bastábamos para mantenerla limpia. A veces llegamos a creer que era ella la que no nos dejó casarnos.

(12) Pero también tuvimos ventajas. La limpieza se simplificó tanto, que aun levantándose tardísimo, a las nueve y media por ejemplo, no daban las once y ya estábamos de brazos cruzados. Irene se acostumbró a ir conmigo a la cocina y ayudarme a preparar el almuerzo. Lo pensamos bien, y se decidió esto: mientras yo preparaba el almuerzo, Irene cocinaría platos para comer fríos de noche. Nos alegramos porque siempre resulta molesto tener que abandonar los dormitorios al atardecer y ponerse a cocinar. Ahora nos bastaba con la mesa en el dormitorio de Irene y las fuentes de comida fiambre.

(13) Aparte de eso todo estaba callado en la casa. De día eran los rumores domésticos, el roce metálico de las agujas de tejer, un crujido al pasar las hojas del álbum filatélico. La puerta de roble, creo haberlo dicho, era maciza. En la cocina y el baño, que quedaban tocando la parte tomada, nos poníamos a hablar en voz más alta o Irene cantaba canciones de cuna.

Cortázar (1976:9-11)

Es indudable que CT permite desarrollar actividades variadas mediante los fragmentos propuestos, puesto que en ellos son evidentes los mecanismos gramaticales y las familias de relaciones. Debido a la limitación especial, no se ha desarrollado por extenso todas las posibilidades que ofrece el relato; sin embargo, se ha mostrado que las familias de relaciones de semejanza, de ampliación y de causalidad son la base del mismo. El docente de E/LE puede trabajar las familias de estas relaciones dependiendo del problema de cohesión textual que haya detectado en el aula. 


\subsection{El relato Circe}

El relato Circe es perfecto para un acercamiento tanto hacia la mitología clásica (el personaje homónimo de Homero) como a los procesos de referencia que se basan en la relación de significados. En contraposición al relato mítico (donde Delia es seguida por los animales), Cortázar presenta a unos amantes que sucumben, salvo en el caso de Mario que, sabedor de las muertes anteriores, piensa que será capaz de romper el hechizo. Este preámbulo de la historia ya puede servir para captar la atención de los discentes y para formular las primeras hipótesis y predicciones sobre el mismo.

El paratexto (The Orchard-pit de Dante Gabriel Rosetti) tiene una doble finalidad: por una parte, es una declaración de afinidades estéticas; por otra, representa una clave para la comprensión del relato. Además, se vincula con las fuentes textuales: la clásica (ya mencionada en el mito) y la romántica (influenciada en John Keats).

El punto de vista adoptado en el relato es esencial para poder relacionarlo con los mecanismos gramaticales, focalizados en la deixis personal (con el uso de la primera persona), y en el valor anafórico (de la tercera persona). Se puede trabajar a partir de estos pequeños fragmentos con los discentes de E/LE:

(14) Yo me acuerdo mal de Delia. Era fina y rubia, demasiado lenta en sus gestos (yo tenía doce años y el tiempo y las cosas son lentas entonces).

(15) Yo me acuerdo mal de Mario, pero dicen que hacía linda pareja con Delia.

(16) Ahora ya es más difícil hablar de esto, está mezclado con otras historias que uno agrega a base de olvidos menores, de falsedades mínimas que tejen y tejen por detrás de los recuerdos.

(17) Había que cerrar los ojos para adivinar el sabor, y Mario obediente cerró los ojos y adivinó un sabor a mandarina, levísimo, viniendo de lo más hondo del chocolate.

Cortázar (1976:125-126)

Delia Maraña está a medio camino entre la locura y la hechicería, el placer y la peligrosidad, mientras que Mario se siente atrapado en la hermosura demoníaca de su presencia. Como ejemplo práctico, se puede ver uno de los mecanismos de cohesión textual a través de la progresión temática y de la palabra clave "bombones":

(18) Delia se quedó mirando la caja y no hizo mucho caso de los bombones, pero cuando estaba comiendo el segundo, de menta con una crestita de nuez, le dijo a Mario que sabía hacer bombones. Parecía excusarse por no haberle confiado antes tantas cosas, empezó a describir con agilidad la manera de hacer los bombones, el relleno y los baños de chocolate o moka. Su mejor receta eran unos bombones a la naranja rellenos de licor, con una aguja perforó uno de los que le traía Mario para mostrarle cómo se los manipulaba; Mario veía sus dedos demasiado blancos contra el bombón, mirándola explicar le parecía un cirujano pausando un delicado tiempo quirúrgico. El bombón como una menuda laucha entre los dedos de Delia, una cosa diminuta pero viva que la aguja laceraba. Mario sintió un raro malestar, una dulzura de abominable repugnancia. "Tire ese bombón”, hubiera querido decirle.

(19) Pensó en los bombones que Delia volvía a ensayar y que se alineaban para secarse en una repisa de la antecocina. Algo le decía a Mario que Delia iba a conseguir cosas maravillosas con los bombones.

(20) Pero a la visita siguiente - también de noche, ya en la sombra de la despedida junto al piano- le permitió probar otro ensayo. Había que cerrar los ojos para adivinar el sabor, y Mario obediente cerró los ojos y adivinó un sabor a mandarina, levísimo, viniendo desde lo 
más hondo del chocolate. Sus dientes desmenuzaban trocitos crocantes, no alcanzó a sentir su sabor y era sólo la sensación agradable de encontrar un apoyo entre esa pulpa dulce y esquiva.

(21) Todavía faltaban ensayos, había cosas sutiles por equilibrar.

(22) Delia dejó que la acompañara hasta la cocina para buscar unos bombones nuevos. Cuando encendió la luz, Mario vio el gato dormido en su rincón, y las cucarachas que huían por las baldosas. Se acordó de la cocina de su casa, Madre Celeste desparramando polvo amarillo en los zócalos. Aquella noche los bombones tenían gusto a moka y un dejo raramente salado (en lo más lejano del sabor) como si al final del gusto se escondiera una lágrima; era idiota pensar en eso, en el resto de las lágrimas caídas la noche de Rolo en el zaguán.

(23) Con la mano libre apretó apenas los flancos del bombón, pero no lo miraba, tenía los ojos en Delia y la cara de yeso, un pierrot repugnante en la penumbra. Los dedos se separaban, dividiendo el bombón. La luna cayó de plano en la masa blanquecina de la cucaracha, el cuerpo desnudo de su revestimiento coriáceo, y alrededor, mezclados con la menta y el mazapán, los trocitos de patas y alas, el polvillo del caparacho triturado.

Cortázar (1976:134)

El relato comienza con una estrategia narrativa que atrapa al lector (lo desconocido para generar la historia) y se desarrolla a través de relaciones discursivas centradas, sobre todo, en la causalidad y el contraste («porque ya no ha de importarle, pero esa vez le dolió la coincidencia de los chismes entrecortados, la cara servil de Madre Celeste contándole a tía Bebé, la incrédula desazón en el gesto de su padre»). Los mecanismos léxico-semánticos constituyen el eje vertebrador del personaje dual de Delia a través de los ojos de Mario, este enfoque es lo aconsejable para que sea trabajado en el aula con los discentes de E/LE. Es conveniente que el alumno se familiarice con la familia de relaciones de semejanza (en este caso, la relación de contraste y de reformulación del inicio del relato) y con la familia de relaciones de causalidad (sobre todo con las relaciones de causa y resultado que van llevando hacia el destino trágico de los personajes).

\subsection{El relato Segunda vez.}

En este cuento son importantes los mecanismos de referencia, y más concretamente, aquellos rasgos que relacionan el texto con el contexto lingüístico en su función discursiva. Estos procedimientos son frecuentes para avanzar y ampliar la información y se presentan a través de una dicotomía pronominal: los unos (nosotros, los funcionarios del Ministerio) y los otros (la gente citada). La impersonalidad del sujeto se establece con las continuas referencias al pronombre indefinido («cada uno tenía su fecha y su hora» / "Cada uno tenía su tema»), aunque el peso cohesivo se encuentra a través de los pronombres personales, los tiempos verbales y los elementos anafóricos que inician y cierran el relato:

(1) Nosotros (deíctico personal, plural inclusivo) /Ellos (anafórico personal de $3^{\mathrm{a}}$ plural):

Ellos, claro, no podían saber que los estábamos esperando»/ «nosotros los recibíamos de a uno como corresponde, con todo el tiempo necesario.

Cortázar (1976:120)

(2) La convocatoria:

«María Elena la había mirado muchas veces en su casa, el sello verde rodeando la firma ilegible y las indicaciones de fecha y lugar». 
(3) Ella (anafórico personal de $3^{\mathrm{a}}$ singular) / Nosotros (deíctico personal):

Antes de irse (había esperado un rato, pero ya no podía seguir así) pensó que el jueves tendría que volver. Capaz que entonces las cosas cambiaban y que la hacían salir por otro lado, aunque no supiera por dónde ni por qué. Ella no, claro, pero nosotros sí lo sabíamos, nosotros la estaríamos esperando a ella y a los otros, fumando despacito y charlando mientras el negro López preparaba otro de los tantos cafés de la mañana.

Cortázar (1976:121)

Cortázar emplea la anáfora asociativa como elemento de cohesión textual en dos momentos del relato: primero, en la descripción de la entrada al edificio; segundo, en la contraposición de los barrios. Esta manera de relacionar los mecanismos lingüísticos también redunda en su coherencia y en su tejido cohesivo en estos dos ejemplos:

(24) La entrada era angosta como todas en la cuadra, con un zaguán de mayólicas y la escalera al fondo; la chapa en la puerta parecía apenas la de un médico o un dentista, sucia y con un papel pegado en la parte de abajo para tapar alguna de las inscripciones. Era raro que no hubiese ascensor, un tercer piso y tener que subir a pie después de ese papel tan serio con el sello verde y la firma y todo.

(25) María Elena también había vivido en Floresta pero de chica, ahora vivía por Constitución. A Carlos no le gustaba ese barrio, prefería el oeste, mejor aire, los árboles.

Cortázar (1976: 12)

Este relato es interesante para trabajar las señales textuales que permiten identificar las relaciones discursivas. En estos ejemplos se puede observar de qué manera estas señales anafóricas actúan como mecanismos referenciales (las anáforas correferenciales y asociativas junto con los deícticos textuales), con la finalidad de desarrollar la progresión constante del texto.

\subsection{EI relato La noche boca arriba}

Un último ejemplo es el cuento La noche boca arriba, donde se expresa la dualidad espacio-temporal a través de dos deícticos temporales contrapuestos (Aquí/Allí). El protagonista no se da cuenta hasta el final del relato de cuál es el sueño y cuál es la realidad, porque el sueño es justamente lo real, es decir, el joven que está a punto de ser sacrificado. Este juego temporal es lo primero que tenemos que trabajar con los discentes de $\mathrm{E} / \mathrm{LE}$, valgan como ejemplo estos fragmentos:

(26) Volvió bruscamente del desmayo. Cuatro o cinco hombres jóvenes lo estaban sacando de debajo de la moto. Sentía gusto a sal y sangre, le dolía una rodilla, y cuando lo alzaron gritó, porque no podía soportar la presión en el brazo derecho. Voces que no parecían pertenecer a las caras suspendidas sobre él, lo alentaban con bromas y seguridades. $\mathrm{Su}$ único alivio fue oír la confirmación de que había estado en su derecho al cruzar la esquina.

(27) Como sueño era curioso porque estaba lleno de olores y él nunca soñaba olores. Primero un olor a pantano, ya que a la izquierda de la calzada empezaban las marismas, los tembladerales de donde no volvía nadie. Pero el olor cesó, y en cambio vino una fragancia compuesta y oscura como la noche en que se movía huyendo de los aztecas.

(28) Lo que más lo torturaba era el olor, como si aun en la absoluta aceptación del sueño algo se revelara contra eso que no era habitual, que hasta entonces no había participado del juego. 
«Huele a guerra», pensó, tocando instintivamente el puñal de piedra atravesado en su ceñidor de lana tejida.

(29) Como dormía de espaldas, no lo sorprendió la posición en que volvía a reconocerse, pero en cambio el olor a humedad, a piedra rezumante de filtraciones, le cerró la garganta y lo obligó a comprender. Inútil abrir los ojos y mirar en todas direcciones; lo envolvía una oscuridad absoluta. Quiso enderezarse y sintió las sogas en las muñecas y los tobillos. Estaba estaqueado en el suelo, en un piso de lajas helado y húmedo.

Cortázar (1993:159)

En el nivel discursivo se propone un final que desmonta las expectativas del lector y provoca la sorpresa. Es un buen momento para analizar esta dicotomía a través de las relaciones de familias discursivas, basadas en el contraste y la causalidad. El mismo cierre del relato es un ejemplo paradigmático de la metáfora sinestésica que sirve de base para las redes asociativas:

(30) Pero olía la muerte, y cuando abrió los ojos vio la figura ensangrentada del sacrificador que venía hacia él con el cuchillo de piedra en la mano. Alcanzó a cerrar otra vez los párpados, aunque ahora sabía que no iba a despertarse, que estaba despierto, que el sueño maravilloso había sido el otro, absurdo como todos los sueños; un sueño en el que había andado por extrañas avenidas de una ciudad asombrosa, con luces verdes y rojas que ardían sin llama ni humo, con un enorme insecto de metal que zumbaba bajo sus piernas. En la mentira de ese sueño también lo habían alzado del suelo, también alguien se le había acercado con un cuchillo en la mano, a él tendido boca arriba, a él boca arriba con los ojos cerrados entre las hogueras.

Cortázar (1993: 168)

El relato está construido desde la base de una relación antitética y de contraste, donde el sujeto bitemporal va entremezclándose tanto en el presente como en el futuro, con el objetivo de llegar a un final aparentemente sorpresivo. Cortázar prepara diferentes clímax temporales que se van interrelacionándose a través de los mecanismos cohesivos gramaticales (sobre todo de tiempos y modos verbales, de la precisión léxica y de la modalidad enunciativa empleada). Estas señales no anafóricas se unen con otros tipos de mecanismos referenciales (las anáforas asociativas), para crear la atmósfera del relato.

El autor describe detalladamente las acciones del personaje y del mundo que lo rodea. Al principio del relato, Cortázar recrea una realidad separada de la segunda, pero esta última se irá entrelazando con la primera y ocupará más espacio narrativo conforme avance la historia. La transgresión viene marcada por el juego de contrastes entre las dos realidades hasta que solamente una de ellas permanezca, para ello se ha construido un eje temporal flexible de continuos cambios que no impide que el lector pueda seguir el hilo argumental, es decir, se trata de una red de asociaciones semánticas precisas que acotan cada una de las realidades hasta que una de ellas prevalece. Esta alternancia de niveles narrativos se realiza con las relaciones de discurso mediante paralelismos y contrastes, además de un uso deliberado de señales anafóricas.

\section{Conclusiones}

Se puede considerar que la narrativa del escritor es una búsqueda continua de diferentes mundos con la idea de reemplazar los conceptos por las metáforas. Las narraciones analizadas sirven como herramienta discursiva para el aprendizaje del español y el 
profesor puede lograr que el estudiante experimente con la lengua y desarrolle una sensibilidad especial hacia el idioma que desea y/o necesita aprender.

Los contenidos literarios son significativos en la clase de E/LE pero hay que tener presente que el discente tendrá más dificultades que un nativo en su dominio de la lengua, en su conocimiento cultural y en la tradición hermenéutica. Para ello, se requiere que el docente utilice una serie de recursos y estrategias discursivas con el objetivo de que el aprendiente adquiera esta pragmática literaria necesaria, respetando su nivel de dominio lingüístico; y en este sentido, los mecanismos de cohesión textual son imprescindibles.

Las familias de relaciones de semejanza, continuidad y ampliación son importantes desde el eje de la cohesión léxico-gramatical, porque no solamente inciden en la estructuración del relato sino también en la organización de mecanismos que facilitan el aprendizaje autónomo del discente a la hora de elaborar su discurso. Los mecanismos de referencia, los elementos deícticos y anafóricos, la dimensión bitemporal, el juego de contrastes, la estructura paralela, el uso de la elipsis y la pretendida impersonalidad del sujeto, van formando una red asociativa donde las relaciones lógicas, sobre todo las de causalidad y contraste, son los ejes vertebradores. Estas redes asociativas trabajan los elementos cohesivos y dan lugar a la transgresión.

\section{Bibliografía}

AlONSO BELMONTE, Isabel (2004). «La subcompetencia discursiva». Sánchez Lobato, J. y Santos Gargallo (dirs.); Vademécum para la formación de profesores. Enseñar español como segunda lengua (L2)/lengua extranjera (LE) (pp. 553-572). Madrid: Ed. Sgel.

Álvarez Garriga, Carles (ed.) (2014). Clases de literatura. Barcelona: Punto de lectura.

BACHMAN, Lyle (1990). Fundamental Considerations in Language Testing. Oxford: Oxford University Press.

BIEDMA TORRECILlas, Aurora (2007). «¿Cómo integrar la literatura en el contexto de Segunda Lengua?». Boletín Millares Carlo, número 26, 241-260. Recuperado el 13/3/2018, de: https://dialnet.unirioja.es/servlet/articulo?codigo $=2592827$

CAMPRA, Rosalba (2008). Territorios de la ficción. Lo fantástico. Sevilla: Renacimiento.

CANALE Y SWAIN, Michael (1983). «De la competencia comunicativa a la pedagogía comunicativa del lenguaje». En Llobera, $\mathrm{M}$ et al.; Competencia comunicativa. Documentos básicos en la enseñanza de lenguas extranjeras (pp. 63-81). Madrid: Ed. Edelsa.

CONSEJO DE EUROPA (2002). Marco común europeo de referencia para las lenguas extranjeras, enseñanza, evaluación. Madrid: Anaya. Recuperado el 10/3/2018 de: www.cervantes.es

CORTÁZAR, Julio (1976a). Los relatos. I. Ritos. Madrid: Alianza.

CORTÁZAR, Julio (1976b). Los relatos II. Juegos. Madrid: Alianza.

CORTÁZAR, Julio (1976c). Los relatos III. Pasajes. Madrid: Alianza. 
CORTÁZAR, Julio (1993). Final del juego. Madrid: Alfaguara.

DUQUE, Eladio (2016). Las relaciones de discurso. Madrid: Arco/Libros.

Instituto Cervantes (2006). Plan curricular del Instituto Cervantes, Niveles de referencia para el español. (Tres volúmenes), Madrid: Biblioteca Nueva.

RuIZ CAmpIllo, José Plácido (2011). Gramática básica del estudiante de español. Barcelona: Ed. Difusión.

YURKIEVICH, Saúl (2004). «Diez razones para leer a Cortázar». Revista de la Universidad de Méjico, 30-51.

ZEPPEGNO, Giuliana (2013). «Transgresión lógica y semántica en la literatura fantástica contemporánea: análisis de unos relatos de Julio Cortázar a la luz de la bi-lógica de Ignacio Matte Blanco». Dicenda, Cuadernos de Filología Hispánica. Universidad Complutense de Madrid, 271-305. 